\title{
O Olho e a Névoa Consideraçōes sobre a teoria do teatro
}

\author{
Ângela Materno
}

Isso, à primeira vista, parece claro. Mas, à medida em que os olhos se detêm, vai ficando obscuro. Na verdade, quanto mais os olhos se detêm, mais obscuro fica. Até que os olhos se fecham e, livre da observação atenta, a mente indaga. Que significa isso? Que, afinal, significa isso, que parecia claro à primeira vista? Até que a mente também dá a impressão de se fechar. Como se fecharia a janela de um quarto escuro e vazio. A única janela que dá para a escuridão exterior. Depois, nada mais. Não. Infelizmente, não. Restam ainda os tênues lampejos de luz, e a agitação. A busca cega e indefinida da mente. Incessante.

Samuel Beckett - Companhia

Temos que nos exercitar para um ato visual complexo.

Bertolt Brecht - "Notas sobre a Opera de três vintens"

\section{A teoria como inquietação do olhar}

$\int^{\prime}$ e não há como negar que "todo olho traz consigo sua névoa" (Didi-Huberman, 1998: 77), tornando assim o ato de ver uma luta com o que parcialmente vemos, com o que não vemos ainda, ou jamais, e com o que nos olha no que vemos ${ }^{1}$ - e se também não é possível ignorar o já tão citado verbo grego theorein (ver), raiz comum das palavras teatro e teoria, associadas, então, por modalidades do visível, talvez se possa pensar inicialmente a noção de teoria do teatro como esse lugar ou momento agonístico em que as visóes do espetáculo, do texto dramatúrgico ou das concepçóes teatrais são expostas às suas próprias névoas - aos seus pressupostos, limites e expectativas. E confrontadas não apenas com outras perspectivas (e embaçamentos), mas também com a luta pela formulação e construção do que é visto, confronto este que desnaturaliza o olhar e desfaz a evidência do objeto.

Ângela Materno é professora do Departamento de Teoria do Teatro, da Escola de Teatro da UNI-Rio.

1 Refiro-me aqui à idéia central do livro $O$ que vemos, o que nos olha, de Georges Didi-Huberman, ou seja, a de que todo ver é marcado por uma cisão entre o que vemos e o que aí nos olha, sendo que isto que nos olha - "e que retorna constantemente no que acreditamos apenas ver" - concerne ao trabalho da perda, ao jogo do esvaziamento. Na primeira frase do primeiro capítulo, diz Huberman: "O que vemos só vale - só vive - em nossos olhos pelo que nos olha" (p. 29). E nmais adiante: " [...] cada coisa a ver, por mais exposta, por mais neutra de aparência que seja torna-se inelutável quando uma perda a suporta - ainda que pelo viés de uma simples associação de idéias, mas constrangedora, ou de um jogo de linguagem -, e desse ponto nos olha, nos concerne, nos persegue." (p. 33). 
Neste sentido, talvez se possa entender a teorizaçáo como o gesto de tensionar os pontos de vista, assim como as categorias e critérios que os constituem, não para conduzir tal conflito a um bom termo, ou a uma síntese apaziguadora, mas para repor em jogo constantemente, e criticamente, os próprios termos e as idéias em questão. Teorizar seria, então, dinamizar as contradiçôes, não para resolvê-las, mas para dar a ver as "cisóes em obra"2 (expressão de DidiHuberman, novamente; cf. 1998: 75).

Sejam feitas, entretanto, duas ressalvas. Em primeiro lugar, dar a ver não significa, aqui, evidenciar o que já estaria previamente - e supostamente - dado (na obra ou no objeto em foco), mas sim constituir, a partir dos embates e da dialética visual que vigoram em todo processo perceptivo, tanto o olhar quanto aquilo que é olhado. Dar a ver é produzir disjunçóes e espaçamentos na aparente inteireza e organicidade do objeto, abrir lacunas em sua espessura, estabelecer suas diferenças e antinomias internas, flagrar o espedaçamento e obscurecimento do visível implicados em tudo o que se mostra. Dar a ver é abismar.

Como destaca Wolfgang Iser, "Não há percepção imediata, como tampouco conhecimento imediato. Ao contrário, é sempre preciso captar um traço do não-dado no dado para que este - qualquer que seja o ponto de vista possa ser apreendido" (Iser, 1996: 119). Ao postular sua teoria do efeito estético, centrada no estudo da obra literária e dos modos de interação entre o texto e o leitor, Iser observa que este último "recebe" o sentido do texto ao constituí-lo (Iser, 1996; 51), pois o que emerge da experiência ficcional e literária, e dos atos de apreensáo do texto, é "o não-idêntico ao de antemāo existente no mundo" (Iser, 1996: 53), é o que resulta da assimetria e hiatos existentes entre o leitor e a obra, e dos vazios e indeterminaçōes a ela inerentes. Tarefa da teoria é, então, a meu ver, construir uma atuação reflexiva que, sempre atenta à relação do pensamento consigo mesmo, procure articular a formulação de conceitos e perspectivas de abordagem com a permanente sinalização crítica do momento e do lugar a partir dos quais o que se vê é visado. Tarefa que inclui construção e problematização incessantes destes dois horizontes: o que se estende diante de nossos olhos e o que forja o nosso olhar.

Em segundo lugar - esta é a segunda das duas ressalvas mencionadas anteriormente - a dinamização das contradiçóes a que me refiro como outro dos gestos teóricos implica também uma espécie de dinamização às avessas, que, por um lado, partilha com Baudelaire a concepção de que o movimento náo se dá apenas no deslocamento - "Odeio o movimento que desloca as linhas", diz o poeta - (Baudelaire, 1972: 32; poema "La Beauté"), e por outro, entende, como Walter Benjamin, que "pensar não inclui apenas o movimento das idéias, mas também sua imobilizaçāo" (Benjamin, 1987: 231). Assim sendo, dinamizar as contradiçōes não significa apenas ou necessariamente articulá-las por meio de relaçōes temporalmente extensivas, mas

2 Tendo como um dos núcleos centrais de sua reflexão a análise de obras minimalistas, como os cubos negros de Tony Smith, por exemplo, Georges Didi-Huberman, em $O$ que vemos, o que nos olha, recusase a pensar a imagem a partir do dilema entre tautologia e crença (termos do autor) - que seriam modos de tentar evitar a inelutável cisão do ver, refugiando-se aquém ou além desta cisão, e afirmando, portanto, no primeiro caso, que o que se vê é só o que se vê, ou buscando, no segundo caso, superar imaginariamente o que é visto pela afirmação da existência de algo para além das evidências. Considerando que os pensamentos binários, ou os pensamentos do dilema, são incapazes de dar conta da cisão do ver, Didi-Huberman propóe a dialetização do que vemos e do que nos olha a partir de seu ponto de inquietude, de suspensão. 
também acioná-las, e portanto constituí-las (dar a ver), a partir do enfoque das diferentes temporalidades que muitas vezes disputam, interna e intensivamente, uma mesma obra, ou um mesmo período histórico, ou um mesmo pensamento. Dinamizar as contradiçôes significa, neste caso, interromper o fluxo do próprio pensamento, para surpreender, imobilizando, uma "configuração saturada de tensões". ${ }^{3}$ (Benjamin, 1987: 231).

Se recorro mais de uma vez à interlocução com Georges Didi-Huberman é porque considero que ao desenvolver, em $O$ que vemos, o que nos olha, uma teoria da imagem, o autor elabora, também e simultaneamente, uma reflexão sobre a práxis teórica, fazendo com que sua concepção de imagem retorne em uma conceituação da própria teoria e de seus modos de produzir imagens do pensamento. Ao afirmar que a imagem só pode ser pensada ("só há imagem a pensar radicalmente", repete-se em vários momentos do livro) para além das oposiçōes canônicas entre o visível e o invisível, entre o próximo e o distante (oposição pertinente à noção extensiva de espaço), entre o visível e o legível, e para além do princípio usual de historicidade, Didi-Huberman reivindica para o próprio pensamento da imagem - ou seja, para sua teorização - uma espacialidade e uma temporalidade também ambíguas e não fixáveis em noçóes ou dicotomias habituais e simplificadoras. Além disto, atribui à teoria - e ao pensamento que ela projeta - uma dimensão, por assim dizer, quase cênica, já que seus procedimentos reflexivos demandam, segundo o autor, uma determinada disposição espaço-temporal: aquela que escapa dos esquemas duais que balizam a percepção e o conhecimento com alternativas excludentes e redutoras.

E se o pensamento teórico, tal como o compreendo, lida justamente com os lampejos e as névoas que possibilitam e dificultam todo exercício do ver, o trabalho teórico é sempre, então, tateante - não apenas por não se pautar pela clareza definidora, mas também porque sabe que precisa constituir, a cada momento, as condiçóes de possibilidade do próprio pensamento. É tateante como o era, na descrição de Trotsky (citada por Benjamin em um de seus fragmentos) o trabalho de seu pai na seara: " Olho-o comovido. Meu pai faz movimentos simples e completamente usuais, nằo se poderia pensar que estivesse trabalhando; seus passos são iguais, são passos tateantes como se procurasse o lugar onde enfim pudesse começar corretamente." (Benjamin, s/d: 272). O labor do conceito - tarefa da teoria - pressupóe esta contínua e cuidadosa procura pelo lugar de onde olhar, de onde indagar, de onde começar. Pressupóe, portanto, constantes recomeços: necessários para que o pensamento não se detenha no já pensado, no já realizado.

Mas se o pensar teórico, no esforço de visualizaçāo de seus objetos (sejam eles o teatro, a literatura, o conceito de imagem etc), caminha de modo tateante entre interrupçōes e recomeços é porque ao mesmo tempo em que não deve se deter no já alcançado (no já estabelecido), mas sim refundar sua perspectiva a cada confronto com novas paisagens e outros olhares, ele também precisa deter o movimento das coisas e das idéias para que elas possam se tor-

3 É desta imobilização do pensamento em uma configuração marcada por tensōes e ambigüidades que surge, segundo Benjamin, a imagem dialética (em que a imagem é a própria dialética em estado de suspensāo), uma das principais categorias teóricas de seus métodos crítico e filosófico, analisados por Susan Buck-Morss, em seu estudo sobre o Projeto das Passagens, como uma dialética do olhar (BuckMorss, Susan. Dialética do olhar. Walter Benjamin e o Projeto das Passagens. Tradução de Ana Luiza Andrade; revisão técnica de David Lopes de Silva. Belo Horizonte, Editora UFMG; Chapecó, Editora Universitária Argos, 2002) 
nar visíveis. Em um dos trechos do fragmento "Vestiário de máscaras", Walter Benjamin alude à imbricada relação entre imobilização, visibilidade e teatro. Diz ele: "Sempre de novo, em Shakespeare, em Calderón, combatentes preenchem o último ato e reis, príncipes, pagens e séquitos 'entram em cena fugindo'. $O$ instante em que se tornam visíveis aos espectadores os faz deter-se. À fuga das personagens dramáticas, a cena dá voz de alto. " (Benjamin, s/d: 65).

Ao movimento contínuo e fugidio das personagens, a cena - como numa brincadeira de criança - diz “Alto!". E, então, o congela, o imobiliza. E é por meio desta interrupção, quando o olhar dos espectadores as detém, que as personagens tornam-se visíveis. Apropriandome desta imagem, arrisco dizer que a teoria (cujas afinidades etimológicas com o teatro já foram mencionadas) encena - torna visível a partir de determinado enquadramento espaçotemporal - uma luta. Não a que os "combatentes" travavam antes de entrarem no palco, não a luta dos reis e dos príncipes. Mas outra: a luta do olho com o que foge ao seu alcance em tudo o que ele vê; a luta do pensamento para dar forma e consistência ao que "sempre de novo" atravessará, em fuga, o seu campo de visão. $O$ pensar teórico não ignora que lida tão-somente com a possibilidade desses instantes espacializados (pelos pontos de observação e linhas de pensamento) em que a captura da significação de algo é sempre novamente provisória.

As referências a Walter Benjamin, que serão constantes neste texto, devem-se ao fato de que, tanto em seu trabalho como crítico literário (inclusive quando trata de temas teatrais), quanto em suas reflexóes sobre a história, são de fundamental importância as construçōes teóricas de seu pensamento, decisivas para sua produção ensaística. A visada crítica de Benjamin, como assinala Henri Meschonnic, não é somente sobre tal ou qual tema, mas sobre o modo mesmo de significar (Wismann, 1986: 709), ou seja, sobre o modo de armar o pensamento, de formular conceitos e significaçōes. Por outro lado, quando critica, por exemplo, a noçáo de história universal, Benjamin a acusa, justamente, de não ter "qualquer armação teórica" e proceder de forma meramente aditiva. Derivada do historicismo e da concepçáo linear de tempo que lhe é subjacente, a história universal, segundo Benjamin, "utiliza a massa dos fatos para com eles preencher o tempo homogêneo e vazio" (Benjamin, 1987: 231).

Configura-se, assim, na obra benjaminiana, uma indissociável relação entre teoria, crítica e história que me parece relevante apontar, pois embora seja possível diferenciar, em parte, a prática teórica das práticas crítica e historiográfica propriamente ditas, a teoria é impensável sem uma dimensão histórico-crítica. Dimensão histórica que se constitui na medida em que a historicidade é entendida como uma dupla marca, ou seja, indica tanto o momento em que algo aconteceu quanto o momento em que este acontecimento torna-se visível, legível, (re)conhecível e, então, histórico. Como observa Walter Benjamin em O livro das Passagens, "A marca histórica das imagens não indica apenas que elas pertencem a uma época determinada, ela indica sobretudo que elas só chegam à legibilidade em uma época determinada (. . . ) cada Agora é o Agora de uma recognoscibilidade determinada" (Benjamin, 1993: 479).

Dimensão histórica que se constitui, também, na medida em que a historicidade, como propõe Giorgio Agamben no ensaio In Playland: reflections on history and play, seja concebida não como localização cronológica, mas sim como "margem diferencial" entre tempos diversos: entre o "era uma vez" e o "não mais", e entre diacronia e sincronia. "Todo acontecimento histórico representa uma margem diferencial entre diacronia e sincronia, estabelecendo uma relação significativa entre elas" (Agamben, 1993: 75). Se o histórico emerge, portanto, da diferença e colisão entre temporalidades distintas - entre o outrora e o agora (o agora em que o outrora é trazido à cena, é pensado) - a reflexão teórica inevitavelmente o inclui, pois seu modo de pensar jamais anula as diferenças, ou elimina os intervalos. Pelo contrário, parte do prin- 
cípio de que sem eles não há visão nem conhecimento possíveis.

A partir daí, pode-se dizer também que a problematização do visível empreendida pelo pensar teórico faz do estabelecimento da diferença histórica a própria condição de possibilidade das formulaçōes que ele engendra. Pois o próprio momento (a atualidade) da ação reflexiva - o agora do pensamento e da escrita - já supóe e requer a configuração de uma margem temporalmente diferencial, constituída a partir de uma "desatualização do presente". Dialogo aqui com a análise realizada por Irene Cardoso das concepçóes de atualidade e de presente desenvolvidas por Foucault em suas últimas obras. Destacando a distinção que ele estabelece entre essas duas noçóes tendo em vista "sua escolha filosófica de um pensamento crítico que toma a forma de uma ontologia da atualidade" e que, portanto, interroga: "O que é a nossa atualidade? Qual é o campo atual das experiências possíveis?" (Cardoso, 2001: 215). Irene Cardoso, em "Foucault e a noção de acontecimento", argumenta:

Há uma distinção, portanto, entre o presente e o atual, entre o hoje e o agora. $O$ atual é construído a partir de um "certo elemento do presente que se trata de reconhecer", como "diferença histórica". Este reconhecimento, que é o da crítica, da problematização, desatualiza o presente, desatualiza o hoje, no movimento de uma interpelação. Nesse sentido o presente não é dado, nem enquadrado numa linearidade entre o passado e o futuro (Cardoso, 2001: 219).

Nesta perspectiva, a própria reflexão teórica opera uma temporalizaçáo, pois ao atentar para o momento e condiçóes em que interroga seu objeto ela também problematiza a atualidade e viabilidade de sua interrogação, criando, assim, margens, diferenças, espaçamentos temporais no próprio presente em que atua, e fazendo deste presente não só o lugar mas também o objeto de uma problematização. Nesse sentido, como destaca Irene Cardoso em "História, memória e crítica do presente", "a atualidade constitui-se, então, como uma alteridade em relação ao passado e ao próprio presente. Caracteriza-se como um movimento de disjunção desse presente, de uma não-contemporaneidade dele em relação a si próprio" (Cardoso, 2001: 16).

Já a dimensão crítica da teoria advém não só das problematizaçóes que ela instaura - $\mathrm{e}$ inquietam o ver -, e da crise que ela abre na percepção, mas também de seu confronto com objetos e realidades particulares, pois o pensamento teórico não é o que se interessa apenas pelas categorias gerais, ou lida somente com abstrações. Pelo contrário, a teoria organiza seu pensamento no contato e no embate com a concretude das obras e das experiências artísticas. $\mathrm{E}$ só assim poderia fazê-lo, pois a separação entre pensamento e criação (variante da separação entre teoria e prática) já indica a ausência de um olhar teórico e faz parte do equívoco de imaginar que haja reflexão sem corpos (corpus) e criaçáo artística sem pensamento.

\section{A teoria do teatro como provocação}

Se minhas tentativas de conceituar a teoria (visando o campo teatral) privilegiaram, até agora, as formas e as forças de seu empenho em constituir uma práxis reflexiva, e não a focalizaram em sua pluralidade, em suas diversas orientaçōes possíveis - semiológica, sociológica, antropológica etc. -, isto não significa que haja aqui a intenção de estabelecer uma suposta natureza teórica que unifique todas as suas modalidades, ultrapasse suas variaçóes históricas, metodológicas, ideológicas, culturais e supere a multiplicidade de objetos dos quais ela pode se ocupar. Muito longe de qualquer concepçáo essencialista, o que pretendi, na verdade, foi enfatizar que toda percepção ou compreensão de algo é sempre um esforço, uma luta, um trabalho de construção e demolição de perspectivas, e que este esforço e trabalho concernem à reflexão teórica 
são por ela realizados e explicitados. O que significa dizer que a teoria é sempre uma provocação às diversas formas de defesa e de afirmação da espontaneidade e da imediaticidade.

Por contrariar as convicções mais arraigadas e interromper a torrente de idéias que se avolumam desde há muito, por atuar inúneras vezes, portanto, como a pedra no caminho, ou como o rochedo que, no meio do rio ${ }^{4}$, obriga as águas a refluirem e os pensamentos a saltarem de seus leitos e pensarem sobre seu próprio curso, a teoria provoca, não raramente, desconforto, suspeitas, ou mesmo um desprezo irritado que mal disfarça a tola arrogância que se satisfaz com seu estoque de certezas úteis e opiniōes de bolso.

$O$ contracurso da teoria em relação aos conceitos já estabelecidos e já assegurados gera resistências. Ao tematizar a teoria do teatro, e a teoria e o teatro, considero importante assinalar essas resistências, até porque elas ainda se verificam, e de forma algumas vezes acentuada, tanto na esfera da criação e da realização teatrais, quanto no âmbito da formaçáo dos artistas de teatro, como, por exemplo, nos cursos universitários de artes cênicas, onde essas resistências manifestam-se não só em alguns alunos, mas também em alguns professores.

Resistências, desconfianças e preconceito que se materializam em determinados usos vocabulares. Se o adjetivo teórico poucas vezes vem isento de um certo tom acusativo (ou pejorativo) quando escolhido para qualificar projetos ou pontos de vista, o advérbio quase sempre indica algo que não é nem será concretizável, praticável ("Teoricamente. . ."). A teo- ria costuma ser olhada como algo que paira acima da experiência. Mas não acima do bem e do mal, pois ela é, muitas vezes, de modo velado ou explícito, considerada maléfica para o bom andamento da criatividade dos artistas.

Em $O$ demônio da teoria, sugestivo título do livro de Antoine Compagnon ( $O$ demônio da teoria: literatura e senso comum, esse é o título completo), o autor discute, principalmente nos capítulos introdutório e conclusivo, quais seriam, no âmbito da teoria literária (ou da teoria da literatura), as possíveis tarefas e especificidades do primeiro desses dois termos. E mesmo ressaltando que o "impulso teórico" sempre corre o risco de acomodar-se em disciplinas (acadêmicas) compartimentadas e inofensivas, ou deformar-se em manuais explicativos, Compagnon considera que a teoria é eminentemente crítica e opositiva (Compagnon, 1999: 16). E como o objeto de análise do autor são os estudos literários, ele afirma: "Há teoria quando as premissas do discurso corrente sobre a literatura não são mais aceitas como evidentes, quando são questionadas, expostas como construçōes históricas, como convençóes." (Compagnon, 1999: 18).

A substituição da palavra literatura pela palavra teatro não altera o teor provocativo da teoria em relação às concepções e valores mais difundidos Do mesmo modo como esta outra observação de Antoine Compagnon poderia também se referir à importância da teoria na formaçāo teatral: "A teoria da literatura", diz ele, "é uma aprendizagem da não-ingenuidade" (Compagnon, 1999: 24). E neste sentido considero que a teoria pode ser, sim, demoníaca.

4 Remeto-me aqui, explicitamente, à imagem que finaliza a primeira versão (1931) do ensaio de Walter Benjamin sobre Brecht intitulado $O$ que é o teatro épico? Um estudo sobre Brecht. Para conceituar a noção de assombro (estranhamento) no teatro brechtiano, Benjamin o compara ao refluxo produzido pela interrupção ou retesamento "do fluxo real da vida" - "o assombro é este refluxo". Mas também compara o assombro ao rochedo "do qual contemplamos a torrente das coisas" (Benjamin, 1987: 90) e onde ela - a torrente - vem se quebrar. Ainda segundo Benjamin, "o objeto mais autêntico desse assombro é a dialética em estado de repouso" (p. 90-1). 
Fragilizando nossas crenças habituais e nos fazendo perder a inocência, ela nos expulsa do paraíso e nos condena ao trabalho: isto é, à luta do ver e ao esforço da reflexão. No chamado meio teatral a palavra teoria adquire, quase sempre, um sentido bem amplo e passa a abranger o conjunto de estudos, análises e reflexões sobre o teatro. E aí parece persistir, em muitos casos, a velha e injustificada desconfiança de que a visão teórica sobre a obra teatral, por parte do artista ou do espectador, possa prejudicar ou macular seja o processo de sua criação, seja a pretensa espontaneidade de sua apreciação.

Em um texto de 1940, intitulado Notas sobre a escrita realista, Bertolt Brecht comenta a freqüente "superstição dos artistas" em relação à ciência, ao conhecimento e à auto-reflexão. Afirmando que esta "superstição", como ele mesmo denomina, vincula-se ao medo que os artistas teriam de perder sua originalidade, Brecht critica "o pudor religioso com que o escritor se nega a contemplar a origem das suas idéias e dos seus sentimentos" e o "receio de que ele não seja capaz de continuar a ser poeta depois de saber demasiado". (Brecht, 1978: 117). Mais adiante, com a ironia que sempre lhe foi peculiar, arremata: "Os nossos poetas perderam a voz, não tanto em face do livro $O$ Capital, como do próprio capital" (Brecht, 1978: 118).

Quanto à recepção teatral, insiste-se ainda, muitas vezes, na mesma e insustentável tecla: a apregoada fruição espontânea. Só que, a rigor, não existe este olhar absolutamente espontâneo, isento de premissas e expectativas, $e$ relacionando-se direta e imediatamente com a obra. Este suposto olhar é, na verdade, moldado pelas convenções habituais e pelas perspectivas dominantes (táo habituais e dominantes que parecem naturais, não construídas).

Da mesma forma que, como bem observa Patrice Pavis,

A teoria majoritária é a teoria da não-teoria, quer dizer, a conviççáo de que não há necessidade de reflexão global para pensar a prática teatral e que basta apreciar intuitivamente e sem a priori o espetáculo para compreendêlo e usufrui-lo. Esta teoria da não-teoria é majoritária na medida em que ela se apóia em um consenso aparente do público, freqüentemente mantido pelos críticos, e segundo o qual o espetáculo é um bem imediatamente consumível sem preparaçáo prévia, sem técnica de análise construída, sem utilização de uma metalinguagem explícita: ela se dá ares de bom senso e de inocência e não se priva de ridicularizar o jargão dos teóricos abstratos e prolixos (Pavis, 1990: 112).

Considerando-se este comentário de Pavis, a questão que se coloca não é, portanto, "com ou sem teoria?", mas qual teoria? A que não se percebe a si mesma e reproduz automaticamente idéias e critérios adotados pela maioria como se eles brotassem espontaneamente e só tivessem como suporte a intuição e aquilo que se chama de indiscutivel gosto pessoal, ou a teoria que, autoconsciente de seus procedimentos reflexivos, e limites, redesenha, constantemente, seu horizonte crítico no contato e no confronto com aquilo que contempla? A teoria da năo-teoria, que se torna, por isso mesmo, unívoca, homogênea e rígida na certeza de sua intuição do que "é bom" e da validade inapelável do consenso? Ou a teoria que, plural em suas diversas perspectivas críticas possíveis, e sempre recolocadas em xeque, não se crê, em nenhuma de suas formas, totalizante?

Se há atores e encenadores que ainda professam a dicotomia entre teorização e prática teatral é porque não conseguem, penso eu, perceber na teoria esse apelo por uma constante problematização do olhar, das escolhas artísticas realizadas, dos meios expressivos utlizados, do pensamento produzido, e das formas e relaçóes de criação e de produção experimentadas. Problematização esta que se constitui a partir do confronto de leituras, do tensionamento de pontos de vista, da reflexão sobre as experiências artísticas, e da cumplicidade crítica com o processo de criação da obra. Esses atores e encenadores parecem entender a teoria como um 
conjunto fechado de idéias e avaliaçóes (sobre a obra, o autor, seu contexto) completamente exterior ao trabalho artístico propriamente dito. E é a partir desta equívoca concepção que se alega, muitas vezes, que a teoria pode prejudicar ou contaminar a relação (supostamente) direta do artista com a obra em si mesma. Como se ele e ela pudessem se relacionar para além (ou aquém) de qualquer mediaçáo e de quaisquer outros conhecimentos e interpelaçóes.

Mas há também aqueles atores e encenadores que, como José Celso Martinez Corrêa, fazem de suas experiências como artistas e pensadores do teatro o palco de múltiplas inquietaçōes, a partir das quais procuram olhar e pensar a teoria. Em entrevista a Edelcio Mostaço e Fátima Saadi, publicada na revista Folhetim, Zé Celso afirma que o teatro é o lugar de relembrar o poder - da inteligência, da imaginação - que o ser humano tem. E acrescenta:

$O$ teatro tem que tocar nesse poderio mas, para tocar nesse poderio, ele precisa ser lido, interpretado e, para isto, ele precisa demais da teoria do teatro [...] Durante muito tempo, houve um desprestígio muito grande dessa coisa de pensar o teatro [...] a maioria dos atores, principalmente quem vai muito pra televisão, tem uma rejeição pela teoria, pela reflexão. E para o teatro poder ser recebido, é necessária uma atividade crítica... a crítica joga luz no que você faz (Folhetim, 2002: 138).

Mais adiante, explicitando a estreita relação entre produção artística e produção teórica, e apontando para a necessidade de novas perspectivas críticas para que novas propostas teatrais possam se tornar efetivamente visíveis e legíveis, Zé Celso delara: "Eu sinto que, pra muita gente, meu trabalho não tem leitura: a pessoa pode estar de corpo presente ali mas está com os preconceitos dela e aqueles preconceitos não foram trabalhados e ela não vê, não está aqui e agora." (Folhetim, 2002: 139).

E se, portanto, "nunca podemos separar com nitidez o que vemos do que sabemos", como destaca E. H. Gombrich no final de seu livro Arte e ilusão (Gombrich, 1986: 342), então duas das tarefas da teoria sáo: tensionar os limites de nossa visão - nosso olho e nossas névoas - problematizando o que sabemos, e provocar conhecimentos inquietando o nosso olhar. Desta dupla via teórica resultam novos horizontes e novas experiências de visibilidade e de inteligibilidade da arte e do mundo.

No caso específico do Brasil, o desconforto em relação à teoria parece associar-se por um lado, ao culto da personalidade, do talento, do gênio nato, e, por outro, à conseqüente desvalorização do trabalho, que se manifesta, no país, sob as mais variadas formas, inclusive nessa auto-suficiência da intuição e da genialidade tantas vezes preconizada.

Explico melhor: a rejeição ao pensamento teórico e ao que ele tem de laborioso, tateante e precário parece corresponder ao que Sérgio Buarque de Holanda já diagnosticava, em Raizes do Brasil, como "o horror ao vago, ao hesitante, ao fluido, que obrigam à colaboração, ao esforço e, por conseguinte, a certa dependência e mesmo abdicação da personalidade" - traço que, segundo o autor, tem determinado freqüentemente "nossa formação espiritual". Nesta mesma linha de argumentação, Sérgio Buarque ressalta: "Tudo quanto dispense qualquer trabalho mental aturado e fatigante, as idéias claras, lúcidas, definitivas que favorecem uma espécie de atonia da inteligência parecem-nos constituir a verdadeira essência da sabedoria" (Holanda, 1982: 117).

A extrema valorização do talento e a sua contraface - a desconfiança em relaçáo à necessidade de muito trabalho -, não dizem respeito estritamente a uma determinada concepção de artista, mas também ecoam, como mostra Sérgio Buarque, o ranço de certos pontos de vista conservadores:

Mas há traços por onde nossa intelectualidade ainda revela sua missão nitidamente conservadora e senhorial. Um deles é a presunção, ainda em nossos dias táo generalizada entre 
seus expoentes, de que o verdadeiro talento há de ser espontâneo, de nascença, como a verdadeira nobreza, pois os trabalhos e o estudo acurado podem conduzir ao saber, mas assemelham-se, por sua monotonia e reiteração, aos ofícios vis que degradam o homem" (Holanda, 1982: 123).

O exercício da teoria nos âmbitos da criaçáo e da formação teatrais adquire, assim, a meu ver, uma irrecusável importância, pois ao requisitar um contínuo trabalho de reflexão, um esforço de argumentação e uma rotina de estudos e interlocuçóes, ele (o exercício da teoria) propõe um modo diferenciado de entender e realizar a prática teatral. Um modo que, na contramão de certos parâmetros artísticos e culturais fortemente enraizados - e lembre-se que no Brasil a relação entre ator e talento, por exemplo, quase sempre foi dada como evidente -, acaba trazendo para as salas de ensaio e para as salas de aula não apenas o confronto entre perspectivas diversas - inerente, inclusive, à própria multiplicidade de abordagens em que a teoria se configura -, mas também o dissenso politicamente necessário a toda atividade artística e intelectual.

E se a teoria é também a aprendizagem da imprecisão dos olhos e da fragilidade das evidências - "Isso, à primeira vista, parece claro. Mas, à medida em que os olhos se detêm, vai ficando obscuro." -, e se é, ainda, a aprendizagem da irredutível agitação da mente e do caráter nunca definitivo de suas especulaçóes - "Depois, nada mais. Não. Infelizmente, não. Restam ainda os tênues lampejos de luz, e a agitação", então a teoria nos exercita não só para a complexidade do ato visual, mas também para a historicidade de nossas visóes e indagaçóes.

Toda tentativa de definir a teoria do teatro é, de certo modo, uma contradição, pois faz parte da reflexão teórica problematizar e relativizar as definiçóes, mostrando seu caráter precário, provisório. Talvez se possa pensar, entretanto, o que ela não é, principalmente em relação à prática de seu ensino. A teoria do teatro não é nem explicativa, nem generalizante. Não elabora modelos de análise que possam ser aplicados à obra (cênico-dramatúrgica) para dela extrair sua lógica de funcionamento e seu significado supostamente oculto. Também não estabelece os princípios gerais do chamado fenômeno teatral.

A teoria do teatro não coincide com a apresentação dos conceitos fundamentais do teatro (até porque a arte teatral é permanentemente refundada). Também não responde, como muitas vezes se espera ou se imagina, à pergunta "O que é o teatro?" Em primeiro lugar, porque o enfoque teórico, a meu ver, não se coaduna com concepçóes essencialistas. Em segundo, porque no campo atual da criação e da reflexão artísticas e teatrais, no campo atual de nossas experiências possiveis - retornando às formulaçōes de Foucault citadas e analisadas por Irene Cardoso -, a questão dos territórios nitidamente demarcados ou das especificidades inteiramente determinadas talvez não seja aquilo que deva ser pensado. A teoria do teatro solicita, hoje - mais do que nunca, talvez - , a configuração de um espaço reflexivo híbrido, composto de relaçōes e interseçóes críticas com outras formas de expressão artística e com outros campos de conhecimento.

Vale lembrar, por fim, que as obras, propostas e experiências teatrais também produzem a seu modo, e de modo diferenciado, teorias pensamento sobre a arte e o teatro, inquietações do olhar. Na obra de Brecht, por exemplo, a intrínseca relação entre reflexão artística e atividade teórica foi determinante para seu projeto teatral, e certamente muito contribuiu para que a própria idéia de teatro fosse, para o dramaturgo e encenador alemão, algo constantemente problematizável e nunca definitivamente resolvido

Em "Notas sobre a Opera de três vinténs", Brecht faz uma curiosa e instigante sugestão que, até onde sei, nunca foi por ele efetivamente realizada, mas que revela seu propósito de tensionar a idéia e a estrutura convencionais do teatro com uma - digamos assim - provocação 
teórica. Diz ele: “Também na arte dramática há que introduzir as notas de rodapé e a consulta de confronto" (Brecht, 1978: 26). Visando tensionar o palco e o livro - problematizando seus suportes e inquietando o visível e o legível - Brecht propóe que se introduza no teatro o agon da formulação de idéias e o embate dos desdobramentos reflexivos.

Também na quase completa escuridão dos palcos de Beckett, em que cabeças, bocas e corpos parcialmente expostos estão fracamente iluminados, mas estão lá, ainda lá, e sempre lá - pois raramente abandonam a cena -, também nesses palcos em que o visível e o inteligível são tensionados ao extremo, até o limite do possível, do dizível, até o limite do teatralizável, também nesses palcos está em jogo uma teorização do teatro - figurada, por exemplo, no retorno infindável da indagação: Que, afinal, significa isso?

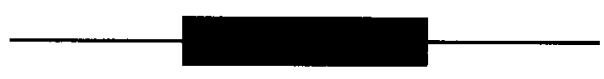

\section{Referências Bibliográficas}

AGAMBEN, Giorgio. "In Playland. Reflections on history and play". In: Infancy and history: essays on the destruction of experience. Londres/Nova York, Verso, 1993.

BAUDELAIRE, Charles. "La Beauté". In: Les fleurs du mal. Paris, Librairie Générale Française, 1972.

BECKETT, Samuel. Companhia. Trad. Elsa Martins. Rio de Janeiro, Francisco Alves, 1982.

BENJAMIN, Walter. "O que é o teatro épico? Um estudo sobre Brecht"; "Sobre o conceito de história" In: Magia e técnica, arte e política. Obras escolbidas volume I. Trad. de Sérgio Paulo Rouanet. São Paulo, Brasiliense, 1987.

. Paris, capitale du XIX siècle. Le livre des passages. Paris, Les Éditions du CERF, 1993.

- "Uma vez só é nada"; "Vestiário de máscaras". In: Rua de mão única. Obras escolhidas volume II. Trad. de Rubens Rodrigues Torres Filho e José Carlos Martins Barbosa. Sāo Paulo, Brasiliense, $2^{\mathrm{a}}$ ed. [s/d].

BRECHT, Bertolt. "Notas sobre a Ópera de três vinténs" In: Estudos sobre teatro. Trad. de Fiama Pais Brandão. Rio de Janeiro, Nova Fronteira, 1978,

. "Notas sobre a escrita realista". In: LUKÁCS, Georg et alii. Realismo, materialismo, utopia (uma polêmica 1935-1940). Lisboa, Moraes Editores, 1978.

BUCK-MORSS, Susan. Walter Benjamin e o Projeto das Passagens. Trad. de Ana Luiza Andrade; revisão técnica de David Lopes da Silva. Belo Horizonte, Editora UFMG; Chapecó, Editora Universitária Argos, 2002.

CARDOSO, Irene. "Foucault e a noção de acontecimento"; "História, memória e crítica do presente". In: Para uma cítica do presente. São Paulo, USP, Curso de Pós-Graduação em Sociologia; Editora 34, 2001. 
COMPAGNON, Antoine. O demônio da teoria: literatura e senso comum. Trad. de Cleonice Paes Barreto Mourão. Belo Horizonte, Editora UFMG, 1999.

CORREA, José Celso Martinez. "Entrevista". In: Folhetim. Teatro do Pequeno Gesto. no 12. Rio de Janeiro, jan.-mar. de 2002.

DIDI-HUBERMAN. O que vemos, o que nos olha. Trad. de Paulo Neves. São Paulo, Editora 34, 1998.

GOMBRICH, E. H. Arte e ilusão: um estudo da psicologia da representação pictórica. Trad. de Raul de Sá Barbosa; revisão de Mônica S. M. da Silva. São Paulo, Martins Fontes, 1986.

HOLANDA, Sérgio Buarque. Raízes do Brasil. Prefácio de Antônio Cândido. Rio de Janeiro, J. Olympio, 1982.

ISER, Wolfgang. $O$ ato da leitura. Uma teoria do efeito estético. vol. 1. Trad. de Johannes Kretschmer. São Paulo, Editora 34, 1996.

MESCHONNIC, Henri. "L'allégorie chez Walter Benjamin, une aventure juive”. In: WISMANN, Heinz (org.). Walter Benjamin et Paris. Colloque international, juin 1983. Paris, Les Éditions du CERF, 1986.

PAVIS, Patrice. "De la théorie considérée comme un des Beaux-Arts et de son influence limitée sur la dramaturgie comtemporaine, majoritaire ou minoritaire". In: Le théatre au croisement des cultures. Paris, José Corti, 1990. 